\title{
An evaluation of pedagogically informed parameterised questions for self assessment
}

\author{
Onjira Sitthisak*, Lester Gilbert, and Hugh C Davis \\ Learning Societies Lab, School of Electronics and Computer Science, University of \\ Southampton, Highfield, Southampton, SO17 1BJ, United Kingdom
}

\begin{abstract}
Self-assessment is a crucial component of learning. Learners can learn by asking themselves questions and attempting to answer them. However, creating effective questions is time-consuming because it may require considerable resources and the skill of critical thinking. Questions need careful construction to accurately represent the intended learning outcome and the subject matter involved. There are very few systems currently available which generate questions automatically, and these are confined to specific domains. This paper presents a system for automatically generating questions from a competency framework, based on a sound pedagogical and technological approach. This makes it possible to guide learners in developing questions for themselves, and to provide authoring templates which speed the creation of new questions for self-assessment. This novel design and implementation involves an ontological database that represents the intended learning outcome to be assessed across a number of dimensions, including level of cognitive ability and subject matter. The system generates a list of all the questions that are possible from a given learning outcome, which may then be used to test for understanding, and so could determine the degree to which learners actually acquire the desired knowledge. The way in which the system has been designed and evaluated is discussed, along with its educational benefits.
\end{abstract}

Keywords: competency, self-assessment, ontology, IMS QTI

\section{Introduction}

We introduce the background to the pedagogical and technological issues involved in automatic question generation. A specific approach is described for the automatic generation of questions in any domain by using a particular model of competencies. A system overview of the proposed competency framework, named COMpetence-Based learner knowledge for personalized Assessment (COMBA), is presented. We consider an implementation of COMBA, an experiment to test its outputs, and the results. Finally, we present some discussion and conclusions. The objectives of this paper are to:

- Present a system for automatically generating questions from a competency framework based on a sound pedagogical and technological approach.

- Present a novel design and implementation with an ontological database that represents the intended learning outcome to be assessed across a number of dimensions such as levels of cognitive ability and subject matter content involved.

- Discuss an evaluation of generated questions against the criteria of clarity, usefulness, challenge, and match with the learning outcomes.

*Corresponding author. Email:os05r@ecs.soton.ac.uk 


\section{Background}

The importance of e-assessment for higher education and research community is well recognised (Matthews 2005). E-assessment involves the use of a computer to support assessment, such as the use of web-based assessment tools. Assessment is a part of the developmental process of learning and is related to the accomplishment of learning outcomes (Kommers, Grabinger and Dunlap 1996). Recently, the main goal of assessment has shifted away from content-based evaluation to intended learning outcome-based evaluation. As a result, through assessment, the focus has shifted towards the identification of learned capability instead of learned content. This change is associated with changes in the method of assessment.

Self-assessment is a crucial component of learning. Dewey observed that learners can learn from asking themselves questions and attempting to answer them (Dewey 1938). The main difficulty for students undertaking self-assessment may be that the number of available questions is insufficient and inadequate for them to assess their knowledge or guide their further study. Creating effective questions is time consuming because it may require considerable resources and skill in critical thinking (McComas and Abraham 2005). The questions have to be carefully defined in order to accurately represent the intended learning outcome and the subject matter content involved. Questions should be appropriate to the learner's level of knowledge based on the concept of a hierarchy of knowledge and their cognitive ability in order to use questioning more effectively as a pedagogical strategy (Gilbert and Gale 2007).

There are currently many systems available to generate questions automatically; these are however confined to specific domains. A number of pioneering systems such as Problets (Dancik and Kumar 2003), QuizPACK (Brusilovsky and Sosnovsky 2005), and Jeliot 3 (Myller 2007) explored the use of automatic generation of questions using parameterised templates. The basic concept uses templates instantiated with random values to generate the questions. A question's template is able to produce a large number of different questions.

Problets and Jeliot 3 generate questions about programming using computer language templates. The question generation of Problets is language independent, whereas Jeliot currently supports only Java. Problets and Jeliot are self-contained, lacking interoperability with other systems such as institutional wide e-learning systems.

QuizPACK works on automatic evaluation of code-execution questions. A teacher provides the core content of a question, a parameterised fragment of code to be executed, and a variable within that code. QuizPACK randomly generates the value of the question parameter, creates a presentation of the resulting question, and runs the presented code in order to generate the correct answer.

These applications of parameterised questions were developed for computer programming. A correct answer to a parameterised question can be calculated by a formula or executed by a standard language complier without the need for a teacher or author to provide it. Currently, such systems offer remarkable automatic generation of questions, but only for specific domains, and lack integration, interoperability, portability and reusability. 


\section{Competence-based model}

The concept of competency is increasingly important since it conceptualizes intended learning outcomes within the process of acquiring and updating knowledge throughout a learner's life (Koper and Specht 2007).

Competency may be defined as the integrated application of knowledge, skills, values, experience, contacts, external knowledge resources and tools to solve a problem, to perform an activity, or to handle a situation (Sandberg 2000; Jackson and Schuler 2003; Friensen and Anderson 2004). On a more practical ground, competency links skills and attitudes with knowledge required from different communities and resources (Paquette 2007).

A competency model supports storing, organising and sharing of achieved, current, and intended performance data relating to all aspects of education and training in a persistent and standard way. This ensures that learners can find learning activities that fit and improve their acquired competencies. In order to support lifelong learning, existing assessment systems have to focus on representation and updating a variety of knowledge domains, rules, assessments and learner's competency profiles.

The interesting points in a competency model are considered as follows (Sitthisak, Gilbert and Davis 2007). First, competency should be defined with a rich data structure for description, comprehensive reference, and exchange to support the maintenance of a learner's competency profile throughout their life. In order to assess learned capabilities and perform competency gap analyses, it should support the recording of competency achievements and of the attainment of intended learning outcomes.

Second, meeting personal needs requires highly flexible competency-based learning. Many learners have different roles, proficiencies, preferences, abilities and backgrounds. A good competency model should support such personalisation.

Third, monitoring and recording a learner's competency is important for selecting suitable questions in an adaptive assessment system. Mechanisms for selecting questions are based on learning progress and decisions about the further direction of the learning process. A good competency model should support straightforward transformations between competency statements and assessment of such competencies.

Fourth, competency should be concerned with specific, identifiable and measurable behaviours (Draganidis and Mentzas 2006). A good competency model should enable the creation of assessments by transforming learned capabilities to question statements, and thus support the automatic expression of relevant assessments for individual and group competencies.

The adoption of electronic competency records and their interoperability may be enhanced by adherence to emerging standards for competency definition. Existing elearning competency standards such as the IMS Reusable Definition of Competency or Educational Objective (IMS RDCEO) specification and the HR-XML standard are not able to accommodate complicated competencies, link competencies adequately, support comparisons of competency data between different communities, or support tracking of the knowledge state of the learner (Sandberg 2000; Hersh et al. 2006; Sitthisak et al. 2007). We proposed an improved competency model named 
COMpetence-Based learner knowledge for personalized Assessment (COMBA) (Sitthisak, Gilbert et al. 2007).

In the first stage of developing the model, we conceptualised "competency" as involving a capability associated with a given subject matter content, requiring a proficiency level, and associated with evidence, any required tools, and a definition of the situation which contextualizes the competency. In the second stage of developing the model, we implemented an exemplar UK Royal College of Nursing competency (UK Royal College of Nursing, 2005) reflecting relevant features of a learner's behaviour and knowledge that affected their learning and performance. An outcome of this implementation exposed a critical issue involving the expression of ethical practice within the COMBA model. One of the conceptions of competence for a nursing graduate is competence in ethical practice (Ramritu and Barnard 2001) as well as the other characteristics of professional service delivery involving knowledge and psychomotor skill (Defloor et al. 2006). Hence, attitude, the way in which a learner exhibits their knowledge and skill, is included in the COMBA model, as illustrated in Figure 1.

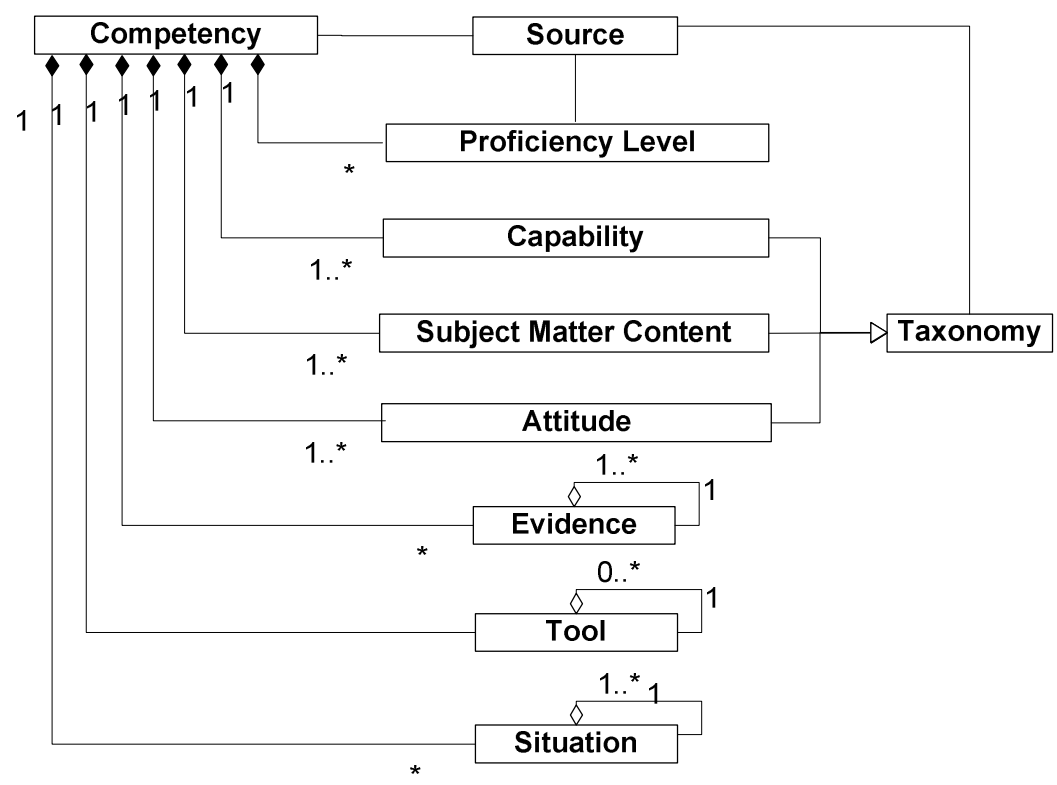

Figure 1 Competency model including attitude component

We focus on how to represent competency as a rich data structure. The heart of this model is to treat knowledge, not as possession, but as a contextualized multidimensional space of capability either actual or potential. The improved competency model is represented in Figure 1 and involves three important elements: an orientation towards and focus upon activity-based teaching and learning; the identification and integration of appropriate subject matter content within a broader teaching and learning context represented by a hierarchy of competencies; and the 
straightforward identification of the assessment that would demonstrate successful teaching and learning.

The COMBA model involves a capability, its association with subject matter content, any attitudinal components, a proficiency level, evidence, any required tools, and a definition of the situation or context of the competency. Each competency, proficiency level, capability, attitude, and subject matter content has a source, an ontology or taxonomy, to which these elements may be referred.

Capability is behaviour that can be observed such as the cognitive capabilities of Bloom's taxonomy (Bloom and Krathwohl 1956). Subject matter content is the subject domain of what the learner can do characterised as a hierarchy of knowledge (Merrill 1983) is applied. Attitude is the way in which a learner exhibits their knowledge and skill, perhaps categorised using a version of Krathwohl's taxonomy (Krathwohl and Anderson 2002). Proficiency level indicates the level of proficiency that learners should or do possess in a particular competency. The competency evidence substantiates the existence, sufficiency, or level of the competency, and might include test results, reports, evaluations, certificates, or licenses. External knowledge resources and tools may be required to support and promote the problem solving, activity performance or situation handling of the competency. The situation identifies the particular context and conditions of the competency, for example, its time limit.

\section{System overview}

COMBA aims to provide a system which is able to accommodate complicated competencies, link competencies adequately, and support tracking of the knowledge state of the learner. The system focuses on the identification and integration of appropriate subject matter content (represented by a hierarchy of competencies) and cognitive ability (represented by a capability taxonomy). This makes identification of the assessment that would demonstrate successful teaching and learning straightforward.

The system was built upon an ontological database that describes all resources and the relationships between them. The advantage of ontological schemas over database schemas is that ontological schemas define explicit formal specifications and include machine-interpretable definition to share common understanding of the structure of information among people or software agents (Antoniou and Harmelen 2004). Thus, the ontological database is flexible and extensible, allowing the resources in the system to be described on the Semantic Web, interoperability between different systems, and reasoning about the described resources.

An assessment for a competency often actually tests component competencies. For example, a statistics course may test knowledge of the confidence interval by testing the learners' ability to calculate, explain, and define the confidence interval in a variety of situations. A generic assessment item can be directly formulated from a competence specification by using the parameters of that competence: capability, subject matter content, and other elements such as the situation. For example, the assessment corresponding to the learning outcome, "students understand the concept 
of a confidence interval" might be something like "Calculate the confidence interval for the following situation", "Explain the importance of the confidence interval in the following situation", or "Define "standard error"". The assessment items of this system adhered to the IMS Question and Test Interoperability specification (IMS QTI). QTI facilitates the sharing of questions and tests, and thus enables investment in the development of common tools such as web-based assessment tools (IMS QTI 2006).

COMBA consists of a number of modules (illustrated in Figure 2): competence navigator, subject matter navigator, capability navigator, question assembler, question to QTI schema converter and sequencing manipulator. The competence navigator is responsible for retrieving the requested competence based on the domain request from the user, and passing the competence to the subject matter and capability navigator modules. The relevant subject matter and capability data received from those modules, together with the authoring question template files, are assembled to generate questions derived from the matrix of competencies crossed with cognitive abilities. Then, the questions are formatted according to the QTI standard, enabling the sharing of the questions and tests. In order to develop a test, the generated questions are linked together for storing in a test bank. For the delivery of the assessment, the system deploys an assessment delivery service (ASDEL) ${ }^{1}$ to allow a learner to view a question and answer it. In the next stage of the research, the system will be extended to marking and feedback.

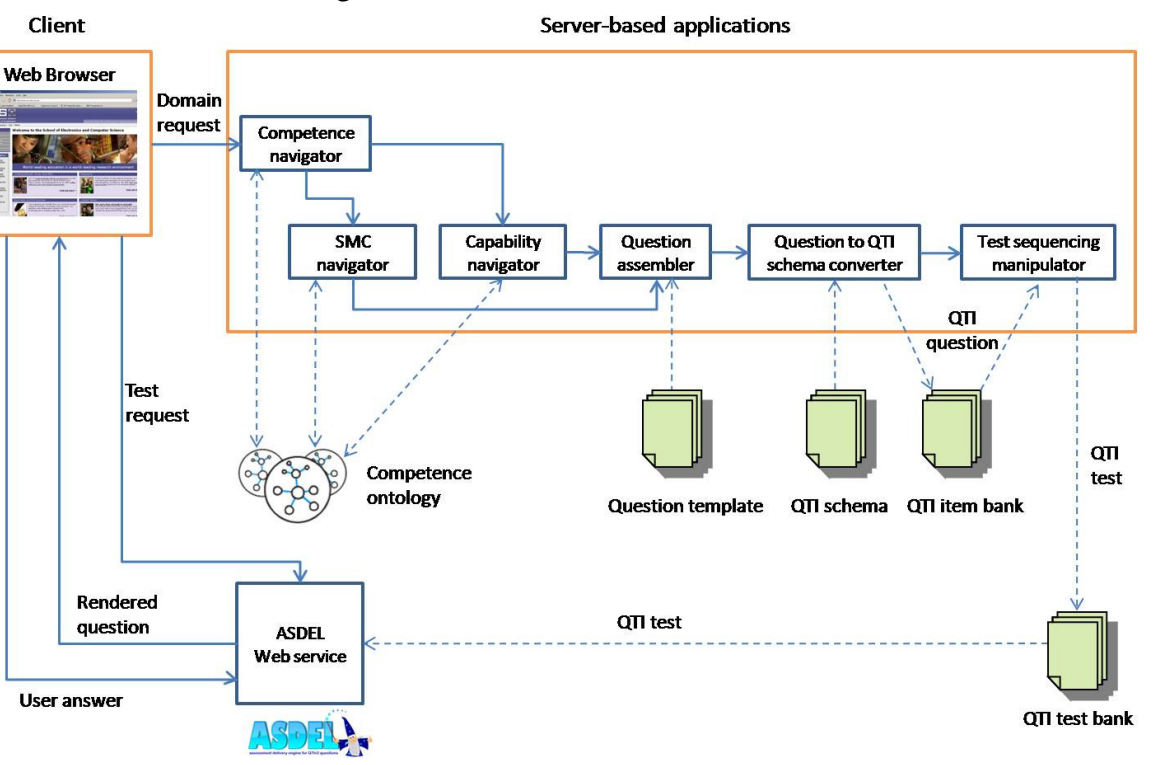

Figure 2 Architecture for the COMBA system

The following section presents data creation, representation and storage, methods of generating and standardizing questions, and methods of question delivery in the COMBA system.

\footnotetext{
${ }^{1}$ http://www.asdel.ecs.soton.ac.uk/
} 


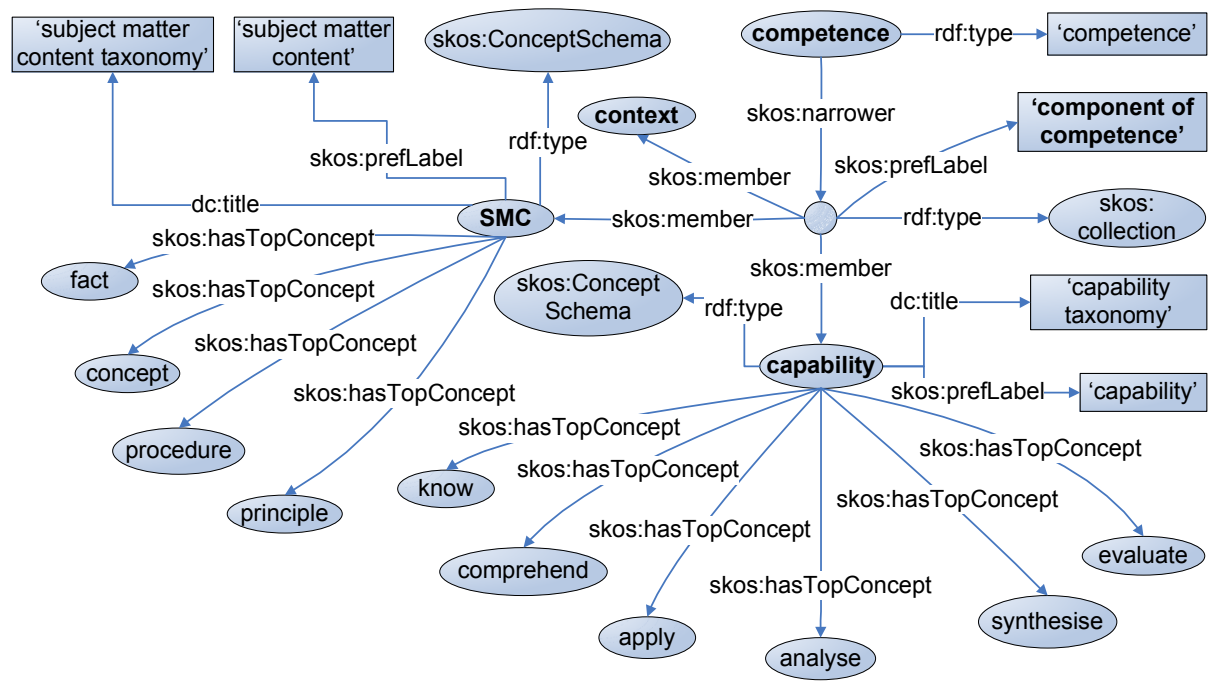

Figure 3 Ontology of COMBA

Table 1 the definitions of each element in the competence ontology.

\begin{tabular}{|c|c|}
\hline Class & Definition \\
\hline Competence & $\begin{array}{l}\text { Defines a capability associated with subject matter content, a proficiency } \\
\text { level, evidence, any required tools, and definition of the situation which } \\
\text { contextualises the competency. }\end{array}$ \\
\hline SMC & $\begin{array}{l}\text { Defines the subject domain of what the learner can do by the end of the } \\
\text { unit of teaching and learning. }\end{array}$ \\
\hline Capability & $\begin{array}{l}\text { Defines behaviour that can be observed, based on a taxonomy of learning } \\
\text { such as Bloom's, Gagné's nine areas of skill, or Merrill's cognitive } \\
\text { domain. }\end{array}$ \\
\hline Context & $\begin{array}{l}\text { Defines the particular context and conditions of the competency, such as } \\
\text { tools and situations. }\end{array}$ \\
\hline Fact & $\begin{array}{l}\text { Defines statements, or factual information which consists of an attribute } \\
\text { and a value. }\end{array}$ \\
\hline Concept & $\begin{array}{l}\text { Defines a group of objects or ideas which are designated by a single word } \\
\text { or term. area concept has a number of attributes which are used to classify } \\
\text { or categorise objects according to their values on those attributes. }\end{array}$ \\
\hline Procedure & Defines a sequential set of steps to accomplish a task or make a decision. \\
\hline Principle & $\begin{array}{l}\text { Defines cause-effect relationships describing the behaviour of a system. It } \\
\text { can usually be expressed as some sort of an equation if the system is in the } \\
\text { scientific or engineering domain. }\end{array}$ \\
\hline Know & \multirow{6}{*}{ Cognitive domain capabilities according to Bloom } \\
\hline Comprehend & \\
\hline Apply & \\
\hline Analyse & \\
\hline Synthesise & \\
\hline Evaluate & \\
\hline
\end{tabular}




\section{Data creation, representation and storage}

The domain subject matter content, capability taxonomy, and competence were represented based on Simple Knowledge Organisation System (SKOS)(W3C 2005).

A domain expert expressed domain content, the capability taxonomy, and competence in an English-like form. A knowledge engineer represented these elements in the form of a semantic network, and then transformed them into an ontology. The ontologies adhered to the criteria of ontology design: clarity, coherence, extendability, minimal encoding bias, and minimal ontological commitment (Kalfoglou 2001). These ontologies are domain, not structure, ontologies using a controlled vocabulary from SKOS (Jovanovic, Gasevic and Devedzic 2006). Sharing and reuse of information are integral aspects of the Semantic Web. In the COMBA system, the ontology was based on Semantic Web technology standards of RDF (W3C 2002) and OWL (W3C 2004). The ontology of the COMBA system is shown in Figure 3. The definitions of the elements in the competence ontology are shown in Table 1.

\section{Method of generating questions and standardising questions}

In any unit of teaching and learning, there are usually a number of competencies intended to be achieved by learners. These competencies and their linkages may be assembled into trees. While the relationship between competence nodes may be modelled as a family relation such as parent and child, there is no necessary ordering of the nodes on the same level, thus yielding a tree structure rather than a hierarchy. Given competencies assembled as a tree structure, it is assumed that proficiency in all children of a defined competency is a necessary precondition for achieving proficiency in the parent. While the tree structure defines a structure which may be traversed top-down or bottom-up, it does not imply sequencing. For example, a competency tree may illustrate the 'roll up' of the assessment for each competency throughout the tree without implying sequencing of the assessment of same level competencies. The competency tree might be used to drill down into component competencies for the target competency, helping to define what to test and how to test it.

In the system, when learners submit their domain of interest to the system, the competence navigator module navigates the competency using the competency ontological database based on the request, where relevant subject matter and capability nodes are retrieved. In this stage, both breadth-first and depth-first strategies can be implemented. The authoring question templates as shown in Table 5 are provided from a test instructor. The retrieved subject matter and capability nodes and the templates are assembled in questions. The process of traversing competencies, retrieving the relevant nodes and converting to questions are recursive. The generated questions are standardised for conformance to the QTI specification by a conversion process using the QTI schema. Finally, the QTI questions are sequenced using a desired strategy such as breadth-first or depth-first. The resulting test file is a sequenced set of questions.

\section{Method of question delivery}

In this research, ASDEL was deployed as a stand-alone web application in order to deliver the tests to the learners. The test files in the QTI test bank were queried from 
the ASDEL web service. ASDEL is responsible for allowing a learner to view a question and to answer it. The type of a question currently in the system is the essay type, so a teacher has to provide written criticism rather than relying on ASDEL to provide feedback. A Web service API including marking, giving feedback, and retrieving assessment results, will be extended in the next stage of the research.

\section{Experiment}

The experiment was designed to explore the following questions:

- How well are the generated questions rated using the criteria of clarity, usefulness, challenge, and match with the learning outcomes?

- Is there a significant difference in rating according to question type?

- Is there a significant difference in rating according to capability type?

A prototype was developed to demonstrate the generation of assessments from a competency data model. The competencies were collected from INFO1013 IT modeling course at the University of Southampton. We may note that representing competencies based on COMBA could be implemented for any domain, whose competencies can be expressed in forms of subject matter and capability taxonomies. The topics involved confidence intervals and associated issues involving:

- critical z score,

- Alpha value,

- standard error,

- measure of dispersion, and

- $\quad$ sample size.

Subject matter content for the competency data model was collected and represented from the core textbook and website of the course syllabus and reviewed by a domain expert in this field. Table 2, 3, and 4 represent this data.

The system generated 42 questions within the confidence interval topic. These questions were filtered to 25 questions based on two domain experts' selection of the questions which would most appropriately address the experimental questions. In this system, we used the question template file as shown in Table 5, and examples of generated questions are shown in Table 6. The 25 questions were classified according to their type, whether they were 'generic' questions or 'specific' questions (see Table $5)$. There were 15 specific questions and 10 generic questions. There are some questions that the experts would have expected such as "What is the effect of sample size on the width of a confidence interval?" and "When computing a confidence interval, when do you use $t$ and when do you use z?". The topic found in these questions is not directly represented in the intended learning outcome and the subject matter involved. These may be called meta-questions. The use of a question template approach did not allow the generation of such questions.

The questions were distributed among five question papers (questionnaires) in order to reduce the workload and time taken of the students answering the 
questionnaire. Hence, each questionnaire comprised three specific questions and two generic questions.

The questions were also classified according to the type of capability involved. There were three capabilities: Define, Explain, and Calculate. The three 'specific' question types involved one question for each capability, while the two 'general' types involved one question for each of the Define and Explain capabilities.

Table 2 Some examples of statistics competencies represented in the competency model.

\begin{tabular}{|l|l|l|l|l|}
\hline \multicolumn{1}{|c|}{ Competence } & $\begin{array}{l}\text { Subject } \\
\text { Matter }\end{array}$ & Capability & Context & Sub-competence \\
\hline $\begin{array}{l}\text { Students can } \\
\text { calculate the } \\
\text { confidence } \\
\text { interval. }\end{array}$ & $\begin{array}{l}\text { Concept: the } \\
\text { confidence } \\
\text { interval }\end{array}$ & $\begin{array}{l}\text { Apply: } \\
\text { Calculate }\end{array}$ & $\begin{array}{l}\text { Nine hundred (900) } \\
\text { high school first year } \\
\text { students ..assuming a } \\
\text { 95\% confidence level. }\end{array}$ & $\begin{array}{l}\text { Students can } \\
\text { calculate the } \\
\text { standard error. }\end{array}$ \\
\hline $\begin{array}{l}\text { Students can } \\
\text { calculate the } \\
\text { standard error. }\end{array}$ & $\begin{array}{l}\text { Concept: the } \\
\text { standard error }\end{array}$ & $\begin{array}{l}\text { Apply: } \\
\text { Calculate }\end{array}$ & (same as above) & - \\
\hline
\end{tabular}

Table 3 Some examples of subject matter content represented in the competency model based on the statistics context.

\begin{tabular}{|l|l|}
\hline \multicolumn{1}{|c|}{ Subject Matter } & \multicolumn{1}{c|}{ Related issue } \\
\hline Concept: the confidence interval & $\begin{array}{l}\text { Concept: the standard error } \\
\text { Fact: the alpha value } \\
\end{array}$ \\
& Fact: the critical z score \\
\hline Concept: the standard error & $\begin{array}{l}\text { Fact: the measure of dispersion } \\
\text { Fact: the sample size }\end{array}$ \\
\hline
\end{tabular}

Table 4 Some examples of related capability represented in the competency model based on the statistics context.

\begin{tabular}{|c|c|}
\hline Capability & Supporting capability \\
\hline Apply: Calculate & Comprehend: Explain \\
\hline Comprehend: Explain & Know: Define \\
\hline
\end{tabular}

Table 5 Question templates.

\begin{tabular}{|l|l|}
\hline \multicolumn{1}{|c|}{ Question Templates } & Type of Question \\
\hline$[$ Capability issue $]+[$ Subject Matter issue $]$ & Generic Question \\
\hline$[$ Capability issue $]+[$ Related Subject Matter issue $]$ & Generic Question \\
\hline$[$ Capability issue $]+[$ Subject Matter issue $]+[$ Situation issue $]$ & Specific Question \\
\hline$[$ Capability issue $]+[$ Related Subject Matter issue $]+[$ Situation issue] & Specific Question \\
\hline
\end{tabular}

The study gathered data from 27 students taking INFO1013 IT modeling course at the University of Southampton. The participants were voluntary undergraduate students, who were asked to rate each question against four criteria (clear, match to 
learning outcomes, useful, and challenging) on a 3-point Likert scale ('Yes', 'No opinion', and 'No' coded as 1, 2, and 3 respectively). The questionnaires were randomly distributed to all attending students to the students at the end of a lecture. (Thirty students were enrolled and expected, but on the day three students failed to attend.)

Table 6 Example generated questions.

\begin{tabular}{|c|c|c|}
\hline Learning outcome & The questions & Type of Question \\
\hline \multirow{4}{*}{$\begin{array}{l}\text { Students understand } \\
\text { the concept of a } \\
\text { confidence interval, } \\
\text { and can calculate it. }\end{array}$} & Define the meaning of the confidence interval. & Generic Question \\
\hline & Explain the importance of the critical z score. & Generic Question \\
\hline & $\begin{array}{l}\text { Calculate the confidence interval for this } \\
\text { situation: Nine hundred ( } 900) \text { high school first } \\
\text { year students were randomly selected for a } \\
\text { national survey. Among survey participants, the } \\
\text { mean grade-point average (GPA) was } 2.7 \text {, and } \\
\text { the population standard deviation was } 0.4 \\
\text { assuming a 95\% confidence level. }\end{array}$ & Specific Question \\
\hline & $\begin{array}{l}\text { Explain the importance of the standard error in } \\
\text { this situation: Nine hundred ( } 900) \text { high school } \\
\text { first year students were randomly selected for a } \\
\text { national survey. Among survey participants, the } \\
\text { mean grade-point average (GPA) was } 2.7 \text {, and } \\
\text { the population standard deviation was } 0.4 \\
\text { assuming a } 95 \% \text { confidence level. }\end{array}$ & Specific Question \\
\hline
\end{tabular}

\section{Results}

The data from the questionnaire was analysed using SPSS to compare the average ratings of the students of generic questions and specific questions for each rating classification (clear, useful, match to learning outcomes, challenging).

There are four test statistics of the multivariate test. Wilks's Lambda, Hotelling's Trace, the Pillai-Bartlett trace, and Roy's largest root. In this experiment, Wilks's Lambda and Hotelling's Trace are the best for our purpose because group differences are concentrated on the variate of rating classification (Field 2005).

Table 7 Multivariate Test.

\begin{tabular}{|l|c|c|c|c|c|c|}
\hline \multicolumn{1}{|c|}{ Effect } & The statistic method & Value & $\mathrm{F}$ & Hypoth df & Error df & Sig. \\
\hline \multirow{2}{*}{ Question type } & Wilks' Lambda & .888 & 4.023 & 4 & 127 & .004 \\
\cline { 2 - 7 } & Hotelling's Trace & .127 & 4.023 & 4 & 127 & .004 \\
\hline \multirow{2}{*}{ Capability type } & Wilks' Lambda & .940 & 0.992 & 8 & 254 & .443 \\
\cline { 2 - 7 } & Hotelling's Trace & .063 & 0.993 & 8 & 252 & .442 \\
\hline $\begin{array}{l}\text { Question type } * \\
\text { Capability type }\end{array}$ & Wilks' Lambda & .996 & 0.134 & 4 & 127 & .970 \\
\cline { 2 - 7 } & Hotelling's Trace & .004 & 0.134 & 4 & 127 & .970 \\
\hline
\end{tabular}


As can be seen in Table 7, the multivariate tests for differences in rating according to question type, capability type, and the question by capability type interaction showed significance only for differences between question types (Wilks' Lambda $p=0.004$ and Hotelling's Trace $\mathrm{p}=0.004)$.

Table 8 Estimated Marginal Means for Question Type

\begin{tabular}{|c|c|c|c|c|c|}
\hline \multirow{2}{*}{$\begin{array}{l}\text { Dependent } \\
\text { Variable }\end{array}$} & \multirow{2}{*}{$\begin{array}{l}\text { Question } \\
\text { type }\end{array}$} & \multirow{2}{*}{ Mean } & \multirow{2}{*}{ Std. Error } & \multicolumn{2}{|c|}{ 95\% Confidence Interval } \\
\hline & & & & Lower Bound & Upper Bound \\
\hline \multirow[t]{2}{*}{ Clear } & Specific Q & 1.975 & .071 & 1.834 & 2.116 \\
\hline & Generic Q & $1.630(\mathrm{a})$ & .087 & 1.457 & 1.802 \\
\hline \multirow[t]{2}{*}{ Useful } & Specific Q & 1.630 & .071 & 1.490 & 1.769 \\
\hline & Generic Q & 1.759 (a) & .086 & 1.588 & 1.930 \\
\hline \multirow{2}{*}{$\begin{array}{l}\text { Match to learning } \\
\text { outcomes }\end{array}$} & Specific Q & 1.877 & .070 & 1.738 & 2.015 \\
\hline & Generic Q & $1.778(\mathrm{a})$ & .086 & 1.608 & 1.948 \\
\hline \multirow[t]{2}{*}{ Challenging } & Specific Q & 1.346 & .057 & 1.233 & 1.459 \\
\hline & Generic Q & $1.500(\mathrm{a})$ & .070 & 1.361 & 1.639 \\
\hline
\end{tabular}

a. Based on modified population marginal mean.

Table 9 Tests of Between-Subjects Effects

\begin{tabular}{|c|c|c|c|c|c|c|}
\hline Source & Dependent Variable & $\begin{array}{l}\text { Type III Sum of } \\
\text { Squares }\end{array}$ & df & $\begin{array}{l}\text { Mean } \\
\text { Square }\end{array}$ & F & Sig. \\
\hline \multirow{4}{*}{$\begin{array}{l}\text { Question } \\
\text { type }\end{array}$} & Clear & 4.48 & 1 & 4.48 & 10.87 & .001 \\
\hline & Useful & .33 & 1 & .33 & .83 & .37 \\
\hline & $\begin{array}{l}\text { Match to learning } \\
\text { outcomes }\end{array}$ & .15 & 1 & .15 & .37 & .54 \\
\hline & Challenging & 1.33 & 1 & 1.33 & 5.03 & .03 \\
\hline \multirow[t]{4}{*}{ Error } & Clear & 53.56 & 130 & .41 & & \\
\hline & Useful & 52.52 & 130 & .40 & & \\
\hline & $\begin{array}{l}\text { Match to learning } \\
\text { outcomes }\end{array}$ & 51.93 & 130 & .40 & & \\
\hline & Challenging & 34.44 & 130 & .27 & & \\
\hline
\end{tabular}

Table 8 provides the estimated marginal means for the four ratings according to question type, and Figure 4 shows the profile graphs. Table 9 provides the tests of between-subject effects for question type, where it may be seen that there were significant differences in mean ratings of 'Clear' and 'Challenging', but there were no significant differences in mean ratings of 'Useful' and 'Match to learning outcomes'. An inspection of the profile graphs shows that the students rated the clarity of generic questions significantly higher than that of specific questions, while rating the challenge of the specific questions significantly higher than that of the generic questions. The students rated the specific and the generic questions as not significantly different with regard to mean ratings of 'Useful' and 'Match to learning outcome'. 


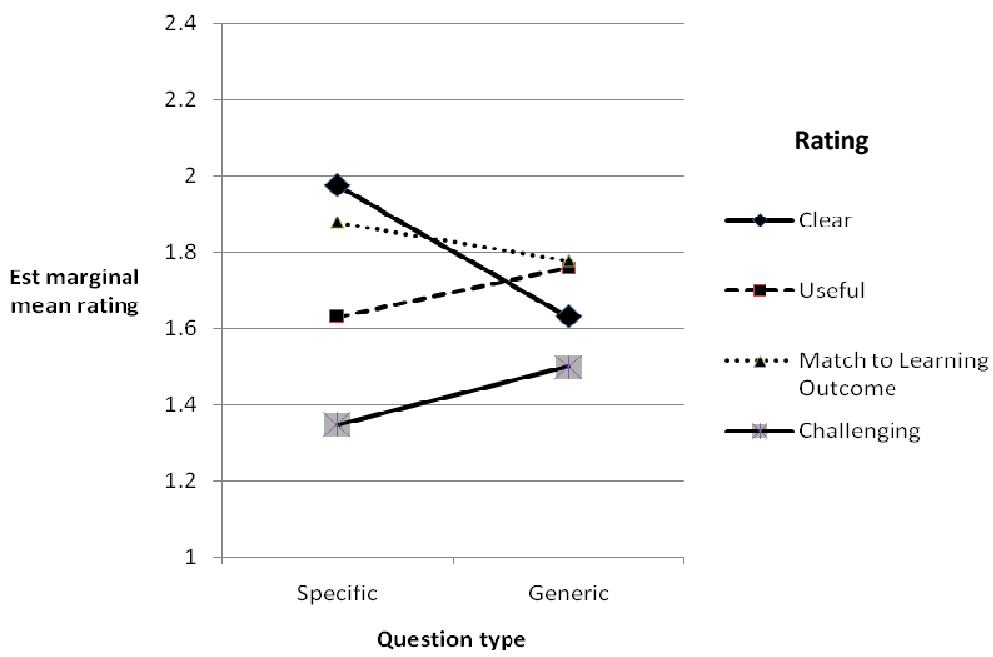

Figure 4 Means profile plots of estimated marginal mean rating for question types

\section{Discussions}

The results indicate that the generated questions were of acceptable value to the students. Six out of eight of the $95 \%$ confidence intervals were below 2 , indicating a tendency to rate "Yes" rather than "No opinion" or worse. That they found the specific questions more useful, and the generic questions more challenging is not an unexpected finding, and neither is the finding that both types of question did not differ significantly on the two other criteria, of their clarity and whether they matched the intended learning outcomes. Interestingly, there was no effect of capability type, and no interaction between capability type (define, explain, and calculate) and question type (specific and generic), indicating that ratings were similar for the three capability types. Overall, the results gave support to the research and suggest that further work would be useful. The following points may be worth discussing.

Although the system can automatically generate a list of all the questions that are possible at various levels from a competency framework, we face the immediate challenge of dealing with representing the subject matter content based on the concept of a hierarchy of knowledge. The hierarchy of knowledge may be classified as fact, concept, procedure, and principle based on Merrill (Merrill 1983). This needs to use a specialist or subject matter content expert to analyse the domain before a knowledge engineer can process it later, and may be regarded as a problem for the current system.

A major challenge in the construction of a competency ontology is that the existing competencies in the course syllabus are required to be well-defined. This is usually not the case in most existing syllabi.

The authoring question template used as the starting point in formulating the format of questions exhibited a rather low efficiency of $59.52 \%$ (the number of the 
generated questions, 42, in relation to the number of selected questions, 25). It may be possible to use some natural language processing for developing the format of questions, and this point will be examined in future work.

The aim of the system was the automatic generation of effective questions, and the construction of a simple sequence of a series of questions for testing. Sequencing could be based upon pedagogical considerations, arranged according to the taxonomies of subject matter content, or of capability, and so on. For example, an adaptive assessment system may start with assessment items at the lower level of the capability taxonomy and progress to the higher levels, in order to reach the boundary of the learner's understanding. On the other hand, sequencing could be based on the learner's preferences. Alternatively, or possibly additionally, regenerating the sequence may be based on the learner's unfolding competences. The result of an adaptive assessment partitions the student's knowledge state into "what the student can do" and "what the student is ready to learn" and finding the boundaries of competence for the learner. Exploring appropriate sequencing is a topic for future work.

\section{Conclusion}

While this study successfully demonstrates a data model and a method of automatically generating acceptable and useful questions, representing competencies and the subject matter is the critical challenge. Successful deployment of the system would require the development of a detailed and systematic database comprising all the competencies involved in the particular domain of interest.

In addition, more effective algorithms are needed for generating questions. The template approach was unable to generate meta-questions, and more advanced methods would be required to accommodate such generation. Furthermore, any generating mechanism must ensure a high standard of English grammar in the resulting questions.

The construction of a sequence or series of questions, that is the construction of an adaptive examination or assessment, is a topic for future work.

We believe that a competency model is critical to successfully managing assessment and achieving the goals of resource sharing, collaboration and automation to support lifelong learning.

\section{Acknowledgements}

This work was partially funded by The Royal Thai Government.

\section{References}

Antoniou, G. and F. v. Harmelen. 2004. A Semantic Web Primer, The MIT Press. 
Bloom, B. S. and D. R. Krathwohl. 1956. Taxonomy of educational objectives: The classification of educational goals by a committee of college and university examiners. New York, Longman.

Brusilovsky, P. and S. Sosnovsky. 2005. Individualized exercises for self-assessment of programming knowledge: An evaluation of QuizPACK. Educational Resources in Computing (JERIC) 5(3).

Dancik, G. and A. Kumar. 2003. A Tutor for Counter-Controlled Loop Concepts and Its Evaluation. Frontiers in Education Conference, USA.

Defloor, T., A. V. Hecke, S. Verhaeghe, M. Gobert, E. Darras and M. Grypdonck. 2006. The clinical nursing competences and their complexity in Belgian general hospitals. Journal of Advanced Nursing 56(6): 669-678.

Dewey, J. 1938. The significance of the Problem of knowledge Logic: The Theory of Inquiry. New York, Holt and Co.

Draganidis, F. and G. Mentzas. 2006. Competency based management: a review of systems and approaches Information Management \& Computer Security 14(1): 51-64.

Field, A. 2005. Discovering Statistics Using SPSS. London, SAGE Publications Ltd.

Friensen, N. and T. Anderson. 2004. Interaction for lifelong learning. British Journal of Educational Technology 35(6): 679-687.

Gilbert, L. and V. Gale. 2007. Principles of eLearning Systems Engineering, Chandos.

Hersh, W. R., R. T. Bhupatiraju, P. S. Greene, V. Smothers and C. Cohen. 2006. Adopting elearning standards in health care: competency-based learning in the medical informatics domain. Proceedings of the AMIA 2006 Annual Symposium.

IMS QTI. 2006. "IMS Question and Test Interoperability Overview." from http://www.imsglobal.org/question/qtiv2p1pd2/imsqti_oviewv2p1pd2.html

Jackson, S. E. and R. S. Schuler. 2003. Managing Human Resources through Strategic Partnerships. Manson, $\mathrm{OH}$, South-Western.

Jovanovic, J., D. Gasevic and V. Devedzic. 2006. Ontology-Based Automatic Annotation of Learning Content. Semantic Web and Information Systems 2(2): 91-119.

Kalfoglou, Y. 2001. Exploring Ontologies, World Scientific Publishing.

Kommers, P., S. Grabinger and J. Dunlap. 1996. Hypermedia Learning Environments. Instructional Design and Integration.

Koper, R. and M. Specht. 2007. TenCompetence: Lifelong Competence Development and Learning. Competencies in Organizational E-Learning: Concepts and Tools. M.-A. Sicilia, Idea Group.

Krathwohl, D. R. and L. Anderson. 2002. A revision of bloom's taxonomy: An overview. Theory into Practice 41(4): 212-218.

Matthews, B. 2005. Semantic Web Technologies. JISC Technology and Standard Watch.

McComas, W. F. and L. Abraham. 2005. "Asking more effective questions." Retrieved October 27, 2007, from http://www.usc.edu/programs/cet/private/pdfs/usc/Asking_Better_Questions.pdf.

Merrill, M. D. 1983. "Component Display Theory." Encyclopeadia of Educational Technology, from http://coe.sdsu.edu/eet/articles/cdt/index.htm.

Myller, N. 2007. Automatic Generation of Prediction Questions during Program Visualization. Electronic Notes in Theoretical Computer Science (ENTCS) 178: 43-49.

Paquette, G. 2007. An Ontology and a Software Framework for Competency Modeling and Management. Educational Technology \& Society 10(3): 1-21.

Ramritu, P. L. and A. Barnard. 2001. New nurse graduates' understanding of competence. International nursing review.

Sandberg, R. 2000. Competence-the Basis for a Smart Workforce. R. Gerber and C. Lankshear (Eds.) Training for a smart workforce. London, Routledge. 
Sitthisak, O., L. Gilbert and H. C. Davis. 2007. Towards a competency model for adaptive assessment to support lifelong learning. TENCompetence Workshop on Service Oriented Approaches and Lifelong Competence Development Infrastructures, Manchester, UK

Sitthisak, O., L. Gilbert, H. C. Davis and M. Gobbi. 2007. Adapting health care competencies to a formal competency model. the ICALT, Niigata, Japan, IEEE Computer Society Press.

W3C. 2002. "Resource Description Framework (RDF)." Retrieved October 27, 2007, from http://www.w3.org/RDF/.

W3C. 2004. "OWL Web Ontology Language (OWL)." Retrieved October 27, 2007, from http://www.w3.org/TR/owl-ref/.

W3C. 2005. "SKOS Core Guide." from http://www.w3.org/TR/swbp-skos-core-guide/. 